\title{
Foundations of RDF Databases ${ }^{\star}$
}

\author{
Claudio Gutierrez \\ Department of Computer Science \\ Universidad de Chile \\ http://www.dcc.uchile.cl/cgutierr/
}

The motivation behind the development of RDF was, to borrow the words Tim Berners-Lee used for the Semantic Web, "to have a common and minimal language to enable to map large quantities of existing data onto it so that the data can be analyzed in ways never dreamed of by its creators." To bring to reality this vision, the processing of RDF data at big scale must be viable. This challenge amounts essentially to develop the theory and practice of RDF databases.

In this talk, we will present the current state of the theory of RDF databases, from the perspective of the work of our (Santiago, Chile) group. We will start discussing the RDF data model from a database perspective [3]. Then we will present the basis of querying RDF and RDFS data, and discuss the pattern matching paradigm for querying RDF 2. (We will also briefly discuss the challenges of viewing RDF from a graph database perspective [1].) Finally we will discuss SPARQL, the recent W3C recommendation query language for RDF, its semantics, expressiveness and complexity [4].

\section{References}

1. Angles, R., Gutierrez, C.: Querying RDF Data from a Graph Database Perspective. In: Gómez-Pérez, A., Euzenat, J. (eds.) ESWC 2005. LNCS, vol. 3532, Springer, Heidelberg (2005)

2. Gutierrez, C., Hurtado, C., Mendelzon, A.O.: Foundations of Semantic Web Databases. In: ACM Symposium on Principles of Database Systems, PODS (2004)

3. Munoz, S., Perez, J., Gutierrez, C.: Minimal Deductive Systems for RDF. In: Franconi, E., Kifer, M., May, W. (eds.) ESWC 2007. LNCS, vol. 4519, Springer, Heidelberg (2007)

4. Perez, J., Arenas, M., Gutierrez, C.: The Semantics and Complexity of SPARQL. In: Cruz, I., Decker, S., Allemang, D., Preist, C., Schwabe, D., Mika, P., Uschold, M., Aroyo, L.M. (eds.) ISWC 2006. LNCS, vol. 4273, Springer, Heidelberg (2006)

\footnotetext{
^ This research is supported by FONDECYT 1070348.
} 